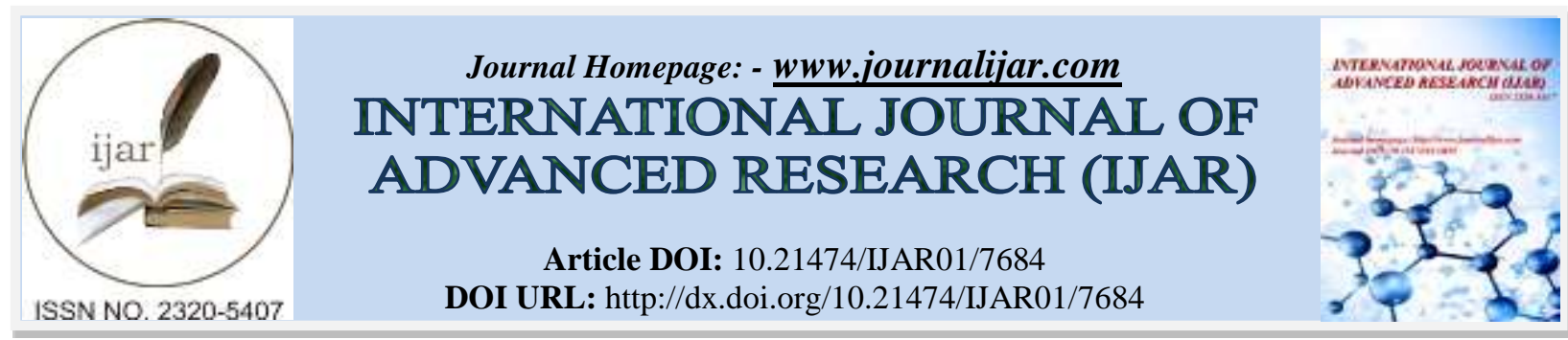

RESEARCH ARTICLE

\title{
PERICARDIOCENTESIS VS SUBXYPHOID PERICARDIOTOMY - COMPARISON OF EFFICACY AND SAFETY
}

\section{Malgorzata Dybowska ${ }^{1}$, Witold Tomkowski ${ }^{1}$, Monika Szturmowicz ${ }^{2}$, Pawel Kuca ${ }^{1}$, Janusz Burakowski ${ }^{1}$, Franciszek Grzegorczyk ${ }^{1}$, Cezary Czajka ${ }^{1}$, Juliusz Gątarek ${ }^{3}$, Piotr Rudziński ${ }^{3}$, Adam Jóźwik ${ }^{4}$ and Renata Langfort ${ }^{5}$.}

1. Cardio-Pulmonary Intensive Care Department, National Institute of Tuberculosis and Lung Diseases, Warsaw/ Poland.

2. I Department of Lung Diseases, National Institute of Tuberculosis and Lung Diseases, Warsaw/ Poland.

3. Department of Thoracic Surgery, National Institute of Tuberculosis and Lung Diseases, Warsaw/ Poland.

4. Computer Science Department, Faculty of Physics and Applied Informatics, University of Łódź/ Poland.

5. Department of Pathology, National Institute of Tuberculosis and Lung Diseases, Warsaw/Poland.

\section{Manuscript Info}

Manuscript History

Received: 18 July 2018

Final Accepted: 24 August 2018

Published: September 2018

\section{Abstract}

Background:-Comparison of safety and effectiveness of pericardiocentesis versus subxyphoid pericardiotomy in patients with large pericardial effusion (PE) defined as more than $2 \mathrm{~cm}$ fluids behind the posterior wall of left ventricle measured by echocardiography.

Methods:-A retrospective analysis was performed on consecutive patients with the diagnosis of large PE hospitalized in the Institute of Tuberculosis and Lung Diseases in 2007- 2017. The analysis included 69 patients.

The effectiveness of therapy was defined as significant decrease of pericardial fluid volume after procedure.

Safety of therapy was assessed by the number of complications like: arrhythmia, respiratory failure requiring respiratory treatment, clinically relevant bleeding, pneumothorax and myocardial injury.

In 18 patients pericardiocentesis was performed. In 51 patients pericardiotomy with pericardial biopsy was indicated.

Results:-In the periprocedual period, in 51 patients on whom pericardiotomy was performed, 12 events ( $23.5 \%$ ) of the prespecified complications occurred. In 7 patients ( $14 \%$ ) paroxysmal atrial fibrillation developed. One patient developed an episode of supraventricular tachycardia. In 2 patients ( $4 \%$ ), the procedure was complicated by the occurrence of respiratory failure, necessitating treatment with mechanical ventilation. In one patient bleeding complication occurred, requiring transfusion. One patient developed left-sided pneumothorax, requiring drainage.

No complications were observed after pericardiocentesis.

In both groups the performed procedures were effective in all patients.

Conclusions:-Rate of complications was higher in the group of patients treated with pericardiotomy comparing to pericardiocentesis $(23.5 \%$ vs $0 \%)$.

Copy Right, IJAR, 2018,. All rights reserved. 


\section{Introduction:-}

Large pericardial effusion (PE) is defined as the volume exceeding $20 \mathrm{~mm}$ of echo-free space behind the posterior wall of left ventricle, measured during echocardiographic examination [1,2]. According to the recent literature, most frequent causes of large PE are: viral pericarditis, post-surgical pericarditis and neoplastic pericardial involvement [1-3]. Large PE requires urgent diagnosis and therapy, especially in patients with signs of threatening cardiac tamponade $[1,2,4]$. Pericardiocentesis as well as pericardiotomy with PE drainage are the methods of choice $[1,2,4]$. However comparison of efficacy and safety of pericardiocentesis and pericardiotomy was assessed only in a few scientific papers [5-8].

Pericardiocentesis is performed under local anesthesia, and it is a "bedside" procedure. It involves the transcutaneous introduction of a needle into the pericardial cavity under control of echocardiography [2,5-8]. For pericardial cannulation, the Seldinger technique is used. The correct position of the needle is assessed by echocardiography $[2,5-8]$.

Pericardiotomy is a more invasive procedure, allowing to take pericardial specimen in patients, in whom etiology of the pericarditis has not been established yet [9]. This procedure requires operating room conditions, appropriate equipment and operator's skills (usually thoracic- or cardiac surgeon) [5-9]. In the course of pericardioscopy a camera is then introduced into the pericardial cavity. The surgeon evaluates the appearance of the internal pericardium wall, endocardium and retrieves from the changed places further specimens for histopathological examinations [9]. From a separate cut or through a wound, a Pezzer's drain is inserted into the pericardial cavity [58].

\section{Patients and Methods:-}

A retrospective analysis was performed on consecutive patients with the diagnosis of large PE confirmed by echocardiography, hospitalized in the Institute of Tuberculosis and Lung Diseases in 2007- 2017.

The analysis included 69 patients ( 31 women and 38 men), mean age 58.2.

In 24 patients neoplastic pericarditis was diagnosed ( positive pericardial fluid cytology, neoplastic infiltration in pericardial specimen or both), and in 45 patients - non- neoplastic pericarditis was recognised.

The effectiveness of therapy was defined as significant decrease of pericardial fluid volume ( determined by echocardiography as less than $5 \mathrm{~mm}$ of fluid behind the left ventricular posterior wall ).

Safety of therapy was assessed by the number of complications like: arrhythmia, respiratory failure requiring respiratory treatment, clinically relevant bleeding, pneumothorax and myocardial injury.

\section{Results:-}

In 18 patients pericardiocentesis was performed (in 5 patients - non-neoplastic pericarditis was diagnosed and in 13 patients with neoplastic involvement of pericardium was confirmed ).

In 51 patients pericardiotomy was performed ( 40 patients with final diagnosis of non-neoplastic pericarditis and 11 patients with neoplastic pericardial effusion).

The procedure was effectivee in all patients treated with pericardiocentesis and with pericardiotomy ( efficacy $100 \%)$.

In the peri-procedural period, in 51 patients in whom pericardiotomy was performed, 12 events (23.5\%) $\mathrm{CI}=[0.1400 ; 0.3676]$ of the pre-specified complications occurred. In 7 patients $(14 \%)$ paroxysmal atrial fibrillation was noted. One patient developed an episode of supraventricular tachycardia. In 2 patients ( $4 \%$ ), the procedure was complicated by the occurrence of respiratory failure, necessitating treatment with mechanical ventilation. In one patient bleeding complication occurred, requiring transfusion. One patient developed left-sided pneumothorax, requiring drainage. 
No complications were observed after pericardiocentesis $(0 \%) \mathrm{CI}=[0.000 ; 0.1759]$ Table1.

Table 1:-Rate of complications in the group of patients treated with pericardiotomy comparing to pericardiocentesis

\begin{tabular}{|l|l|l|}
\hline & $\begin{array}{l}\text { Pericardiotomy } \\
\text { 51 patients }\end{array}$ & $\begin{array}{l}\text { Pericardiocentesis } \\
\text { 18 patients }\end{array}$ \\
\hline Paroxysmal AF & 7 & 0 \\
\hline SVT & 1 & 0 \\
\hline $\begin{array}{l}\text { Respiratory failure requiring ventilation } \\
\text { support }\end{array}$ & 2 & 0 \\
\hline Clinicallyrelevantbleeding & 1 & 0 \\
\hline Pneumothorax & 1 & 0 \\
\hline Myocardialinjury & 0 & 0 \\
\hline Sum & $\begin{array}{l}12(23.5 \%) \\
\mathrm{CI}=[0.1400 ; 0.3676]\end{array}$ & $\begin{array}{l}0 \quad(0 \%) \\
\mathrm{CI}=[0.000 ; 0.1759]\end{array}$ \\
\hline
\end{tabular}

\section{Conclusions:-}

Rate of complications was higher in the group of patients treated with pericardiotomy $(23.5 \%$ vs $0 \%$ ). The authors' experience indicates that pericardiocentesis with $\mathrm{PE}$ drainage is a safer procedure comparing to pericardiotomy with PE drainage.

\section{Discussion:-}

Head- to- head comparison of efficacy and safety of pericardiotomy and pericardiocentesis has not been determined up to the present time in randomized trials [4-6].

It is worth emphasizing that, in the presented group of patients, the efficacy of both pericardiocentesis and pericardiotomy was very high.

Nevertheless, the safety of pericardiotomy was lower than the safety of pericardiocentesis. Serious complications, such as respiratory failure requiring ventilator treatment, and clinically relevant bleeding, occurred only after pericardiotomy.

The preferred recommended treatment of large PE is needle pericardiocentesis with the use of echocardiographic or fluoroscopic guidance. In all of our patients, pericardiocentesis was performed under echocardiographic guidance.

Pericardiocentesis is also recommended for cardiac tamponade, to relive symptoms and establish the diagnosis, especially in patients with suspicion of malignant pericardial effusion.

An alternative method of treatment of large PE is surgical approach, followed by drainage of pericardial sac. Pericardiotomy followed by pericardial, as well as epicardial biopsy should be considered for confirmation of the diagnosis, especially for patients with a suspicion of malignant pericardial involvement.

In our group of patients pericardial biopsy was the main indication for subxiphoid pericardiotomy [10-11].

Due to its' excellent safety, pericardiocentesis seems to be the first-line approach for the treatment of cases with large PE of unknown origin. Pericardiotomy seems to be a less safe procedure and should be reserved for the patients in whom pericardiocentesis and cytological examination of pericardial fluid failed to establish aetiology of pericarditis [9].

\section{Acknowledgement:-}

The authors wish to thank Mrs. Zofia Gadaj for Her help in translating this article into English. 


\section{References:-}

1. Spodick DH. Pericardial diseases. In: Braunwald E, Zippes DP, Libby P, eds (2001) Heart Disease, $6^{\text {th }}$ ed. Philadelphia London Toronto Montreal Sydney Tokyo, W.B. Saunders 1823-76.

2. Maisch B, Seferović PM, Ristić AD, Erbel R, Rienmüller R, Adler Y, Tomkowski WZ, Thiene G, Yacoub MH (2004) Task Force on the Diagnosis and Management of Pericardial Diseases of the European Society of Cardiology. Guidelines on the diagnosis and management of pericardial diseases executive summary; The Task force on the diagnosis and management of pericardial diseases of the European society of cardiology. Eur Heart $\mathrm{J}$ 7:587-610.

3. Pawlak Cieślik A, Szturmowicz M, Fijałkowska A, Gątarek J, Gralec R, Błasińska-Przerwa K, SzczepulskaWójcik E, Skoczylas A, Bilska A, Tomkowski W (2012) Diagnosis of malignantpericarditis: a single centreexperience.Kardiol Pol 70:1147-53

4. Ristić AD, Imazio M, Adler Y, Anastasakis A, Badano LP, Brucato A, Caforio AL, Dubourg O, Elliott P, Gimeno J, Helio T, Klingel K, Linhart A, Maisch B, Mayosi B, Mogensen J, Pinto Y, Seggewiss H, Seferović PM, Tavazzi L, Tomkowski W, Charron P (2014) Triage strategy for urgent management of cardiac tamponade: a position statement of the European Society of Cardiology Working Group on Myocardial and Pericardial Diseases. EurHeart J.35:2279-84

5. Labbé C, Tremblay L, Lacasse Y. Pericardiocentesis versus pericardiotomy for malignant pericardial effusion: a retrospective comparison. CurrOncol. 2015 Dec;22(6):412-6. doi: 10.3747/co.22.2698

6. Palatianos GM, Thurer RJ, Kaiser GA. Comparison of effectiveness and safety of operations on the pericardium. Chest. 1985 Jul;88(1):30-3.

7. Saltzman AJ, Paz YE, Rene AG, Green P, Hassanin A, Argenziano MG, Rabbani L, Dangas G. Comparison of surgicalpericardialdrainage with percutaneouscatheterdrainage for pericardialeffusion.J InvasiveCardiol. 2012 Nov;24(11):590-3.

8. Patel N, Rafique AM, Eshaghian S, Mendoza F, Biner S, Cercek B, Siegel RJ (2013) Retrospectivecomparison of outcomes, diagnosticvalue, and complications of percutaneousprolongeddrainage versus surgicalpericardiotomy of pericardialeffusionassociated with malignancy.Am J Cardiol 112:1235-9

9. Maisch B, Rupp H, Ristic A, Pankuweit S (2013) Pericardioscopy and epi- and pericardialbiopsy - a new window to the heart improving etiological diagnoses and permitting targeted intrapericardial therapy. HeartFailRev 18:317-28

10. Wilson, E. B. "Probable Inference, the Law of Succession, and Statistical Inference," Journal of the American Statistical Association, 22, 209-212 (1927).

11. Newcombe, Robert G. "Interval Estimation for the Difference Between Independent Proportions: Comparison of Eleven Methods," Statistics in Medicine, 17, 873-890 (1998). 